\title{
Prediction of the thermospheric and ionospheric responses to the 21 June 2020 annular solar eclipse
}

\author{
Tong Dang 1,2,3, JiuHou Lei 1,2,3*, WenBin Wang ${ }^{4}$, MaoDong Yan 1,2,3, DeXin Ren 1,2,3, and FuQing Huang 1,2,3 \\ ${ }^{1}$ Chinese Academy of Sciences Key Laboratory of Geospace Environment, School of Earth and Space Sciences, University of Science and Technology of China, \\ Hefei 230026, China; \\ ${ }^{2}$ Mengcheng National Geophysical Observatory, University of Science and Technology of China, Hefei 230026, China; \\ ${ }^{3}$ Chinese Academy of Sciences Center for Excellence in Comparative Planetology, University of Science and Technology of China, Hefei 230026, China; \\ ${ }^{4}$ High Altitude Observatory, National Center for Atmospheric Research, Boulder, CO, USA \\ Key Points: \\ - We present a quantitative prediction of the ionosphere-thermosphere responses to the upcoming 21 June 2020 solar eclipse from \\ model simulations \\ - A prominent total electron content (TEC) enhancement occurs in the equatorial ionization anomaly (EIA) region even when the region \\ is still in the shadow of the eclipse \\ - The increase in TEC in the EIA region is caused by changes in the wind transequatorial transport of plasma induced by the eclipse
}

Citation: Dang, T., Lei, J. H., Wang, W. B., Yan, M. D., Ren, D. X., and Huang, F. Q. (2020). Prediction of the thermospheric and ionospheric responses to the 21 June 2020 annular solar eclipse. Earth Planet. Phys., 4(3), 231-237. http://doi.org/10.26464/epp2020032

\begin{abstract}
On 21 June 2020, an annular solar eclipse will traverse the low latitudes from Africa to Southeast Asia. The highest latitude of the maximum eclipse obscuration is approximately $30^{\circ}$. This low-latitude solar eclipse provides a unique and unprecedented opportunity to explore the impact of the eclipse on the low-latitude ionosphere-thermosphere (I-T) system, especially in the equatorial ionization anomaly region. In this study, we describe a quantitative prediction of the impact of this upcoming solar eclipse on the I-T system by using Thermosphere-lonosphere-Electrodynamics General Circulation Model simulations. A prominent total electron content (TEC) enhancement of around 2 TEC units occurs in the equatorial ionization anomaly region even when this region is still in the shadow of the eclipse. This TEC enhancement lasts for nearly 4.5 hours, long after the solar eclipse has ended. Further model control simulations indicate that the TEC increase is mainly caused by the eclipse-induced transequatorial plasma transport associated with northward neutral wind perturbations, which result from eclipse-induced pressure gradient changes. The results illustrate that the effect of the solar eclipse on the I-T system is not transient and linear but should be considered a dynamically and energetically coupled system.
\end{abstract}

Keywords: solar eclipse; ionosphere-thermosphere coupling; equatorial ionization anomaly; model simulation

\section{Introduction}

A solar eclipse is a special phenomenon in which the Moon moves between the Sun and Earth and casts a shadow on parts of the Earth. By partially blocking the solar extreme ultraviolet (EUV) irradiation, solar eclipses generate dramatic disturbances to the Earth's ionosphere-thermosphere (I-T) system. This phenomenon also provides a unique opportunity to conduct an "active experiment" to explore the basic physics of the I-T system and the response of geospace to this transient event.

The response of the ionosphere to solar eclipses has been investigated for decades by using observational tools such as ionosondes (Chen G et al., 2013; Farges et al., 2001; Le HJ et al., 2008),

Correspondence to: J. Lei, leijh@ustc.edu.cn

Received 18 MAR 2020; Accepted 08 MAY 2020.

Accepted article online 14 MAY 2020.

C 2020 by Earth and Planetary Physics. the global positioning system total electron content (TEC) (Afraimovich et al., 1998; Ding F et al., 2010; Jakowski et al., 2008), satellite measurements (Anastassiadis and Matsoukas, 1969; Singh et al., 1989), and Incoherent Scatter Radar (ISR) (MacPherson et al., 2000; Salah et al., 1986), as well as numerical simulations (Boitman et al., 1999; Le HJ et al., 2008; Roble et al., 1986). Previous studies have illustrated that the ionospheric electron density can be greatly reduced within the shadow of the eclipse because of the reduction in solar EUV irradiation. Recently, the 2017 Great American Solar Eclipse, which passed through the entire continent of United States from west to east, has rekindled interest in the solar eclipse and its effects among both researchers and members of the public (e.g., Zhang SR et al., 2017a). A number of findings, such as traveling ionospheric disturbances and global and long-lasting I-T responses, have been reported because of advances in observational instruments and modeling tools (e.g., Dang T et al., 2018a, b; Harding et al., 2018; Lei JH et al., 2018; Nayak and Yiğit, 2018; Sun YY et al., 2018; Zhang SR et al., 2017b). 
Because the path of the 2017 solar eclipse and those of other recent solar eclipses have mostly been at the middle latitudes or have touched the low latitudes only near dusk, little attention has been paid to solar eclipses that occur in the low latitudes. Some previous works have reported unusual responses of the $F$ region electron density in the low-latitude ionosphere during solar eclipses. Using a low-latitude ionospheric tomography network, Huang CR et al. (1999) found TEC enhancements over the low-latitude ionosphere in the Northern Hemisphere during the 24 October 1995 solar eclipse. Madhav Haridas and Manju (2012) reported an enhanced critical frequency of the ionospheric $F_{2}$ layer $\left(f_{\mathrm{o}} \mathrm{F}_{2}\right)$ over Gadanki from ionosonde data during the solar eclipse on 15 January 2010, and they associated the enhancements with the presence of an equatorial ionization anomaly (EIA) crest as a result of weakened electrodynamics. However, details of the effects of the I-T system on a low-latitude solar eclipse and the underlying physical mechanisms are still unclear. Interactions between the solar eclipse and the low-latitude ionosphere would be worth investigating, especially in the dynamically and electrodynamically coupled EIA region. On 21 June 2020, an annular solar eclipse will traverse the low-latitude ionosphere from Africa to Southeast Asia, with the uniqueness of a pure low-latitude solar eclipse (the maximum latitude of the greatest obscuration is around $30^{\circ}$ ) as compared with other recent solar eclipses. This eclipse provides an ideal opportunity to explore the dynamic and electrodynamic response of the low-latitude ionosphere to eclipses, which has not been fully understood, with the benefit that numerous observational instruments are available in Africa and Asia, including those of the Chinese Meridian Project. In this study, we provide a quantitative prediction of the I-T responses to the 21 June 2020 annular solar eclipse by using the Thermospherelonosphere-Electrodynamics General Circulation Model (TIEGCM). The responses of the low-latitude I-T system to the solar eclipse, especially those in the EIA region, are examined, and the driving physical mechanisms are explored through a series of control simulations.

\section{Methodology}

The National Center for Atmospheric Research TIEGCM is a time- dependent, self-consistent, three-dimensional, global, and physics-based model of the coupled I-T system (Richmond et al., 1992; Roble et al., 1988). The model also solves the ionospheric electrodynamics associated with the neutral wind dynamo, which obtains its electric potential from thermospheric winds and ionospheric conductivity in apex coordinates based on the International Geomagnetic Reference Field (Richmond, 1995). Details on the TIEGCM can be found in Qian LY et al. (2014). The convection pattern at high latitudes is specified by the Heelis model (Heelis et al., 1982), which is driven by the geomagnetic activity $K p$ index.

The solar radiation flux changes during the eclipse are represented by an eclipse factor function, which is calculated by the area ratio where the Sun is masked by the moon (Curto et al., 2006). This eclipse factor function varies with longitude, latitude, and universal time (UT). Note that it also considers the solar EUV radiation from the unmasked part of the corona. That is, even if it is a total eclipse, solar EUV radiation is still emitted from the corona. A detailed description of the eclipse factor calculation is given by Le $\mathrm{HJ}$ et al. (2008). In this study, two TIEGCM simulations with $2.5^{\circ} \times$ $2.5^{\circ}$ longitude-latitude resolution were conducted, one without and the other with the solar eclipse effect. Both simulations were run under a quiet geomagnetic activity condition of $K p=2$ and a solar minimum condition of $F_{10.7}=62.4$, the latter of which was taken from the prediction by the National Oceanic and Atmospheric Administration Space Weather Prediction Center (https://www.swpc.noaa.gov/). The differential TEC, neutral winds, and neutral temperatures between the two simulation runs were calculated to quantify numerically the global ionospheric and thermospheric changes during the 21 June 2020 solar eclipse.

\section{Results and Discussion}

The path of the annular solar eclipse on 21 June 2020 is shown in Figure 1. The eclipse will begin in the Democratic Republic of the Congo in Africa at 04:47 UT, pass through Saudi Arabia, Pakistan, and China, and finally end over the Pacific Ocean at 08:32 UT, with the maximum eclipse obscuration occurring at $30.5^{\circ} \mathrm{N}, 79.7^{\circ} \mathrm{E}$ at 06:40 UT. The partial eclipse covers a much wider range and will be visible for a width of thousands of kilometers from the central

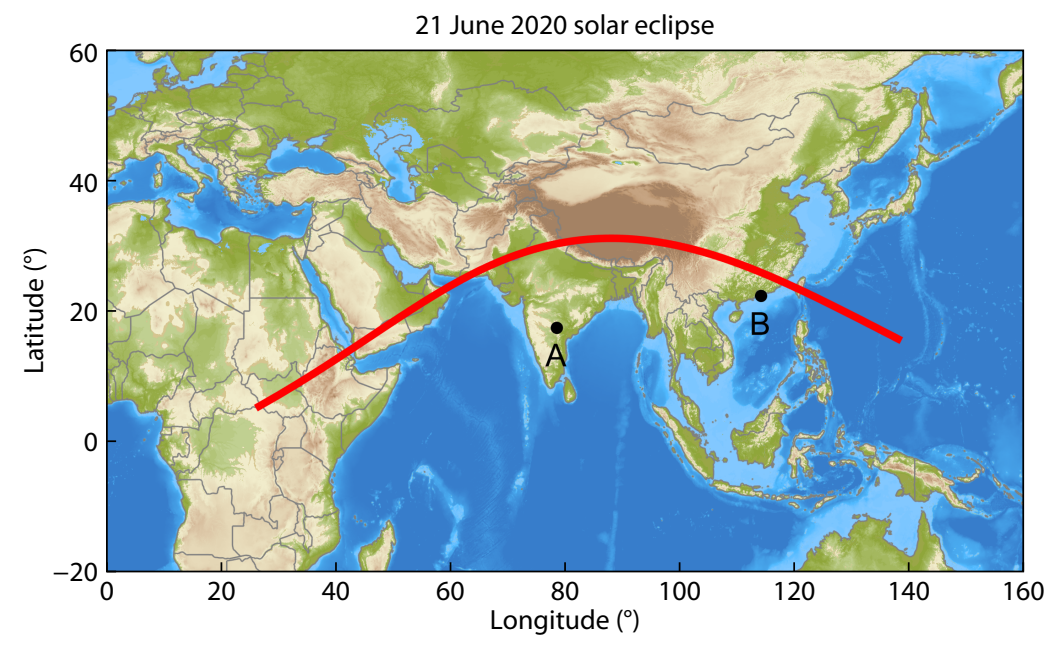

Figure 1. The path of the solar eclipse on 21 June 2020 . The two stations, $A\left(78.6^{\circ} \mathrm{E}, 17.4^{\circ} \mathrm{N}\right)$ and $\mathrm{B}\left(114.2^{\circ} \mathrm{E}, 22.3^{\circ} \mathrm{N}\right)$, are marked with black dots. 
path from 03:51 UT to 09:28 UT. Two stations, A $\left(78.6^{\circ} \mathrm{E}, 17.4^{\circ} \mathrm{N}\right.$; magnetic latitude: $\left.9.0^{\circ} \mathrm{N}\right)$ and $\mathrm{B}\left(114.2^{\circ} \mathrm{E}, 22.3^{\circ} \mathrm{N}\right.$; magnetic latitude: $12.8^{\circ} \mathrm{N}$ ), shown in Figure 1 (marked by the solid black circles) are used later for detailed comparisons.

Figure 2 displays the differences between the TIEGCM simulations with and without the eclipse for the TEC, neutral temperature, and meridional winds to indicate the ionospheric and thermospheric responses to the 21 June 2020 solar eclipse. At 06:40 UT, when it is at the greatest eclipse, the TEC (Figure 2a) will have a maximum depletion of around 3 TEC units (TECU; 1 TECU = $10^{16} / \mathrm{m}^{2}$ ) because of the large and rapid reduction of solar EUV irradiation. Note that the TEC depletion is not exactly aligned with the path of the solar eclipse and the eclipse factor (shown in the auxiliary movie), but with an unrecovered depletion "tail" at latitudes less than $15^{\circ}$ in the Northern Hemisphere. This result indicates that the ionospheric response to a solar eclipse is not merely a reflection of the solar EUV change, but that it involves chemical, dynamic, and electrodynamic effects in the low-latitude ionosphere. The neutral temperature and meridional winds were plotted on a $Z_{p}=2$ constant pressure surface, which is close to the peak height of the ionospheric $F$ region (approximately $300 \mathrm{~km}$ ). The thermospheric temperature (Figure $2 \mathrm{~b}$ ) at the same UT is reduced by about $30 \mathrm{~K}$ because of the large reduction in energy input during the solar eclipse. Consequently, the pressure gradient changes associated with the neutral temperature depletion cause meridional wind (positive northward) perturbations (Figure $2 \mathrm{c}$ ) to converge toward the eclipse region, with southward and northward perturbations on the two sides of the eclipse path.

As time progresses, at 08:40 UT, the annular solar eclipse has ended and only a minor partial solar eclipse remains over the $\mathrm{Pa}$ - cific Ocean. The neutral parameters (Figures $2 \mathrm{e}$ and $2 \mathrm{f}$ ) are generally similar to those at 06:40 UT associated with the movements of the solar eclipse. The temperature and wind perturbations extend toward higher latitudes; the northward wind perturbation at the south of the eclipse path becomes stronger, whereas the perturbations north of the path become weaker. In contrast, the TEC is much different. As shown in Figure 2d, a TEC reduction of 3 TECU can still been seen around Southeast Asia. It is interesting to note that a TEC enhancement (or recovered TEC) of around 2 TECU is prominent in the EIA region, which is surrounded by eclipseinduced TEC depletions, as discussed for 06:40 UT (Figure 2a). As also displayed in the auxiliary movie, this abnormal TEC enhancement begins to appear at 07:30 UT even when the EIA region is still covered by the shadow of the eclipse, and it lasts for nearly 4.5 hours, long after the eclipse has ended. Furthermore, a TEC increase of around 1 TECU can be seen over a large part of the Indian Ocean in the Southern Hemisphere.

At 11:40 UT, 3 hours after the annular solar eclipse has ended, similar TEC perturbations (Figure $2 \mathrm{~g}$ ) still exist but with a smaller magnitude and an expanded range, indicating a long-lasting recovery process, as reported by Lei JH et al. (2018). As shown in Figure $2 \mathrm{~h}$ and $2 \mathrm{i}$, large-scale traveling atmospheric disturbances (TADs) are triggered by the solar eclipse, propagating globally from the northwest to the southeast. It should also be noted, as shown in the auxiliary movie, that the $\boldsymbol{E} \times \boldsymbol{B}$ vertical plasma drifts can be greatly disturbed by the solar eclipse, with a perturbation velocity of around $3 \mathrm{~m} / \mathrm{s}$ at low latitudes, which indicates a global electrodynamic coupling in the I-T system during the solar eclipse. The changes in electron density, ionospheric conductance, and neutral winds induced by the solar eclipse can result in perturbations
06:40 UT
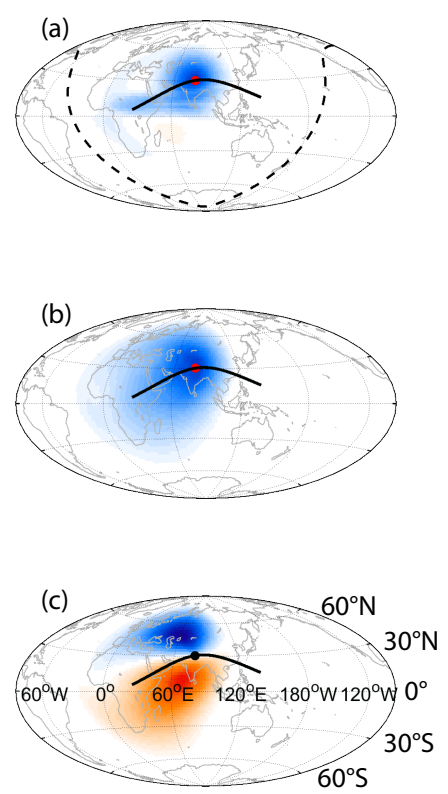

08:40 UT

Total electron content (TECU)

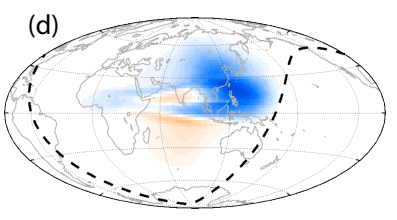

Neutral temperature (K)

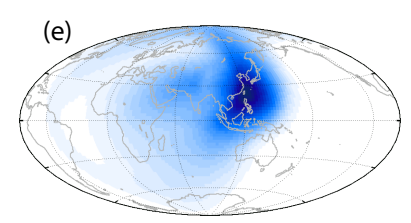

Meridional wind ( $\mathrm{m} / \mathrm{s})$

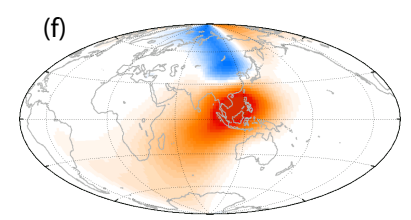

11:40 UT
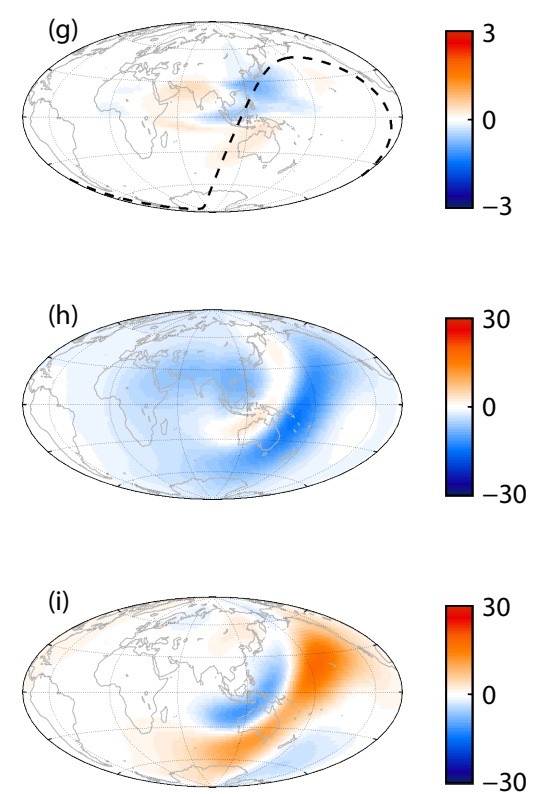

Figure 2. Global maps of the differential (top) TEC, (middle) neutral temperature, and (bottom) meridional wind (positive northward) for three selected UTs (06:40 UT, 08:40 UT, and 11:40 UT). The neutral temperature and meridional wind are plotted at pressure level 2 ( 300 km). The solid circle represents the location of the totality at 06:40 UT. The black and green dashed lines indicate the magnetic equator and solar terminator, respectively. 
of the electric field associated with the ionospheric dynamo process.

The above simulations show that the solar eclipse can lead to TEC depletions, a thermospheric temperature decrease, neutral wind perturbations converging toward the eclipse path, and the generation of large-scale TADs, all of which agree well with other work on solar eclipses (e.g., Dang T et al., 2018b; Huba and Drob, 2017). However, the solar eclipse on 21 June 2020 will have a distinct effect on the low-latitude I-T system, especially on the EIA. A prominent TEC increase was found at the northern crest of the EIA, although it was still in the shadow of the eclipse. This EIA enhancement lasts long after the solar eclipse has ended, which has not been reported in previous studies. The remaining question is how the solar eclipse induces the abnormal TEC enhancement in the EIA region.

As a well-known ionospheric phenomenon, the EIA is mainly due to what is known as the "equatorial fountain effect" (Duncan, 1960; Moffett and Hanson, 1965). The plasma over the equatorial region moves upward because of $E \times B$ drifts and then diffuses downward along the magnetic field lines into both hemispheres. Our results also suggest that meanwhile, the neutral winds modulate the EIA structures, especially their hemispheric asymmetry at solstices via the transequatorial transport effects between the two hemispheres (Dang T et al., 2016; Lin CH et al., 2007; Luan XL et al., 2015). As shown in Figure 2 and the auxiliary movie, the solar eclipse has a substantial impact on the electron density (directly through photochemistry), neutral winds, and $E \times B$ drifts, all of which can contribute to TEC variations in the EIA region during the eclipse. Hence, to investigate the relative contributions of the neutral winds, $E \times B$ drifts, and photochemistry to the abnormal electron density enhancement in the EIA region, a series of numerical control experiments were conducted. We first display the absolute TEC, differential TEC, and differential meridional winds in Figure $3 a-3 c$, which is similar to Figure 2, for a better comparison with the later case-controlled runs. Note that the TEC enhancement (Figure $3 b$ ) caused by the solar eclipse corresponds well to the EIA crest in the Northern Hemisphere (Figure 3a).

For the controlled runs in Figure $3 d-3 f$, we respectively replaced the terms of the neutral winds, $\boldsymbol{E} \times \boldsymbol{B}$ drifts, and photochemistry in the oxygen ion continuity equation from the non-eclipse run and kept the other parameters the same as with the eclipse run to analyze the effects of these terms on the TEC variations caused by the solar eclipse. By comparing the results with the default run (Figure $3 b$ ), we were able to examine the relative contributions from each parameter. When the contribution from the neutral wind perturbations was excluded (Figure 3d), the simulated TEC enhancement in the EIA region disappeared, whereas other features were similar to that in the default run (Figure $3 \mathrm{~b}$ ). The differential TEC turned to negative values in the EIA region, indicating that neutral wind transport plays a significant role in the EIA responses to the solar eclipse and in the enhancement of TEC in the EIA region. This can be explained by the northward neutral wind perturbations (Figure 3c). The northward neutral winds transport plasma from the EIA crest in the Southern Hemisphere to the crest

08:40 UT, 21 June 2020

(a) TEC default

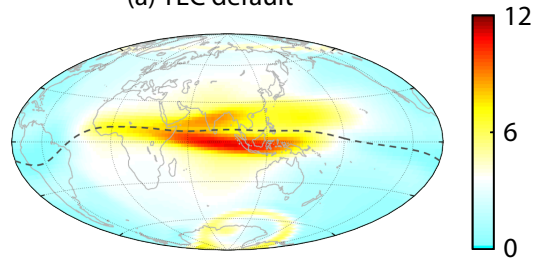

(c) $\triangle \mathrm{VN}$

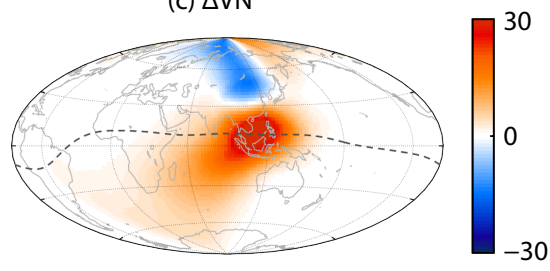

(e) $\triangle$ TEC with non-eclipse $\boldsymbol{E} \times \boldsymbol{B}$

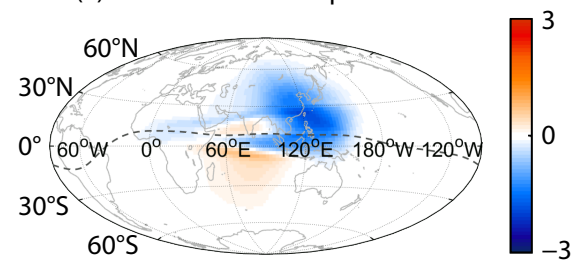

(b) $\triangle T E C$ default

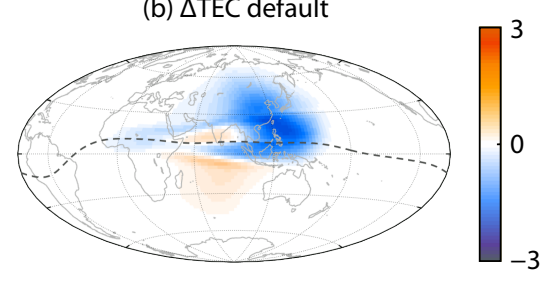

(d) $\triangle T E C$ with non-eclipse wind

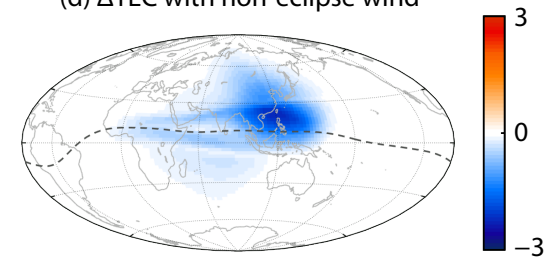

(f) $\triangle T E C$ with non-eclipse photochemistry

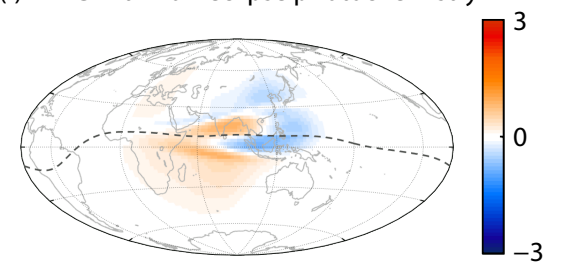

Figure 3. (a-c) Global maps of the TEC, differential TEC, and differential meridional winds from TIEGCM simulations with and without the eclipse (With Eclipse, Without Eclipse) at 08:40 UT. (d-f) Differential TEC from the controlled runs with non-eclipse neutral winds, $E \times B$ drifts, and photochemistry, respectively. The black dashed lines indicate the magnetic equator. The units for TEC and meridional winds are TECU and $\mathrm{m} / \mathrm{s}$, respectively. 
in the Northern Hemisphere, thus resulting in an increase of the TEC in the EIA region (Figure $3 b$ ). Moreover, the electron density enhancement over the Indian Ocean in the Southern Hemisphere turned to an enhancement in this control run. This result indicates that the northward neutral wind perturbation can push plasma to a higher altitude, where the recombination rate is lower, and consequently cause an increase in TEC in the Southern Hemisphere. Depletion of the TEC between the two enhancement regions (Figure $3 \mathrm{~b}$ ) is associated with the unrecovered depletion "tail" at 06:40 UT (Figure 2a) caused by both photoionization and dynamic processes. Meanwhile, the wind-induced EIA TEC decrease in the Southern Hemisphere by the transequatorial transport of plasma also contributes to the depletion.

To examine whether the eclipse-induced electric field changes affect the TEC distribution, a control simulation was then conducted by replacing the $E \times B$ drifts from the non-eclipse run. Unlike the neutral wind-controlled run, the TEC in Figure $3 e$ is almost unchanged as compared with Figure $3 \mathrm{~b}$, indicating that, at least for the TIEGCM simulations, the $\boldsymbol{E} \times \boldsymbol{B}$ perturbations will contribute less to the TEC changes during this solar eclipse. Note that St. Maurice et al. (2011) reported a vertical oscillation of the $F$ region peak at the magnetic equator associated with a counter electrojet during the solar eclipse. They further showed that this westward electric field was due to a local neutral wind dynamo associated with the wind perturbations, which are generated by cold temperatures and a low-pressure system in the region of maximum obscuration. Their findings and our results indicate a complicated electrodynamic process affected by the solar eclipse in the coupled I-T system. Determining when and how the eclipse-disturbed electrodynamics affects the ionosphere requires further investigation. We conducted an additional simulation (Figure $3 f$ ) to test the effect of photochemistry from the solar eclipse. The simulation was similar to the default eclipse run except that the photochemistry term was replaced by the non-eclipse values. When the photochemical effect was removed, the TEC depletion over Southeast Asia that was directly caused by the EUV reduction was greatly weakened. In the EIA region, the TEC exhibited an increase in the Northern Hemisphere and a decrease in the Southern Hemisphere, which corresponds well to the transequatorial transport effect of the neutral wind changes. We then checked whether the neutral component changes in the thermosphere could contribute to the increase in TEC by using the non-eclipse $\mathrm{O} / \mathrm{N}_{2}$ ratio in the eclipse simulations (not shown). The TEC results were almost unchanged as compared with the default run, implying that the neutral compositions contributed less to the eclipseinduced ionospheric variations. Overall, the above results confirm the significant role of the eclipse-induced neutral wind changes in the global ionospheric responses to the eclipse.

In Figure 4, we also display the temporal variations of TEC for stations $A$ and $B$ (marked in Figure 1), both of which have GNSS (Global Navigation Satellite System) receivers and can provide possible observational comparisons for this solar eclipse. The black, red, and blue curves represent the run without the eclipse, the run with the eclipse, and the neutral wind-controlled run, respectively. Note that the magnitudes of the maximum eclipse obscuration for stations $A$ and $B$ are 0.60 and 0.89 , respectively. As shown in Figure 4a, the TEC begins to decrease at 04:42 UT because of the reduction in solar EUV irradiation during the solar eclipse. The TEC then begins to increase at around 07:00 UT, although the station is stilled covered by the shadow of the solar eclipse, with an eclipse obscuration magnitude of 0.51 . The TEC increase maximizes at 10:00 UT and lasts for nearly 4 hours, and finally recovers to the non-eclipse values at around 12:00 UT. This TEC increase is consistent with the TEC enhancement in the EIA region in Figure $2 \mathrm{~d}$ and is associated with the transequatorial neutral wind transport, as discussed above. The wind-controlled run (blue line) further validates the sizable contribution of neutral winds to the electron density or TEC changes, as shown by the drop in TEC during the entire eclipse period. For station B in Figure $4 \mathrm{~b}$, the TEC exhibits a prominent depletion of around $30 \%$ of the non-eclipse values, with the minimum occurring at 08:00 UT. Although the magnetic latitude of station $B$ is low $\left(12.8^{\circ} \mathrm{N}\right)$ and within the EIA region, the local time is already around 16:00 LT (local time) when the solar eclipse touches this station. The magnitude of the EIA crest is relatively low, and the neutral wind effect is not as efficient or as great as that at earlier UTs, yet we can still note a contribution from the neutral wind transport when comparing the red and blue curves.

The effects of the solar eclipse on the I-T system have been dis-
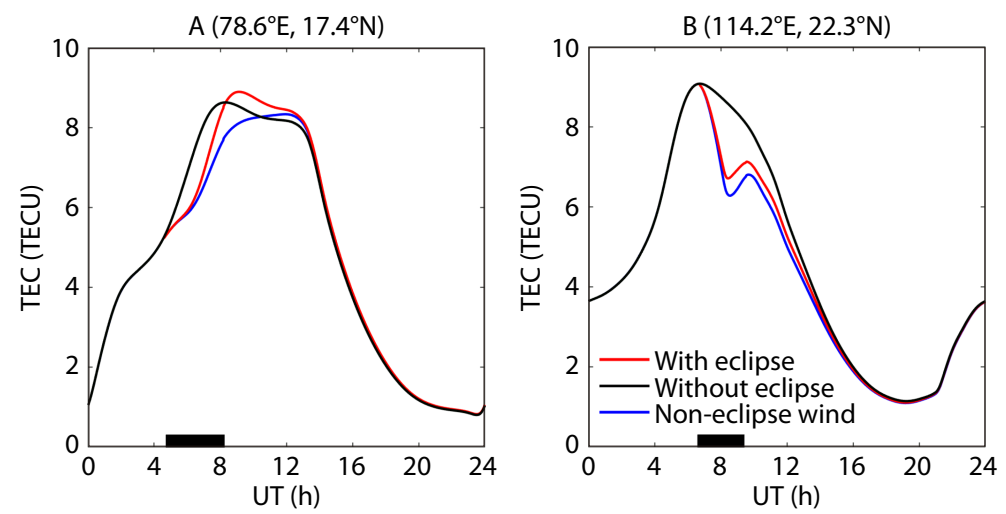

Figure 4. Universal time variations of TEC at stations $A\left(78.6^{\circ} \mathrm{E}, 17.4^{\circ} \mathrm{N}\right.$; magnetic latitude: $\left.9.0^{\circ} \mathrm{N}\right)$ and $B\left(114.2^{\circ} \mathrm{E}, 22.3^{\circ} \mathrm{N}\right.$; magnetic latitude: $\left.12.8^{\circ} \mathrm{N}\right)$. The black, red, and blue curves represent the TIEGCM runs without and with the eclipse and the eclipse run with the non-eclipse neutral winds. The horizontal bars indicate the duration of the solar eclipse over the stations. 
cussed for decades, especially for the recent 2017 Great American Solar Eclipse (e.g., Huba and Drob, 2017; Wang WB et al., 2019). However, most of the recent solar eclipses have occurred at the middle latitudes or have touched low latitudes only near the end of the eclipse, making it difficult to examine the responses of the low-latitude I-T system in the EIA region to the eclipses. Some previous works have reported unusual enhancements of $F$ region electron density in the low-latitude ionosphere during solar eclipses, and most have attributed the physical cause to either electrodynamics or the neutral composition (e.g., Huang CR et al., 1999; Madhav Haridas and Manju, 2012). The upcoming 21 June 2020 solar eclipse directly traverses the EIA region and has ample low-latitude coverage, with a maximum eclipse obscuration latitude of only $30^{\circ}$. This eclipse will provide an ideal opportunity to address the behavior of the EIA during a low-latitude solar eclipse. According to the simulation results, the low-latitude ionosphere does respond differently to a solar eclipse, given that the TEC in the EIA region is enhanced, even when the eclipse occurs in the EIA region and the solar EUV radiation flux is reduced. We further illustrate that eclipse-induced neutral wind perturbations lead to this EIA enhancement through the effect of transequatorial transport.

As indicated in Figures 2-4 as well as in the auxiliary movie, a solar eclipse can affect the I-T system through multiple means. On one hand, a solar eclipse can directly reduce the ionospheric electron density by masking the solar EUV irradiation and decreasing the thermospheric temperature through a reduced energy input. This temperature depletion can then lead to convergent neutral wind disturbances. On the other hand, through the transequatorial transport process, the eclipse-induced neutral wind disturbances further change the distribution of the ionospheric TEC in the EIA region. These findings illustrate that the impact of a solar eclipse on the Earth's I-T system as well as on geospace is not transient, linear, and isolated but rather should be treated as a dynamically, electrodynamically, and energetically coupled nonlinear system. This finding also challenges the direct observations because the data coverage is limited and the pure effect of the solar eclipse on the I-T system is difficult to obtain, considering that it is mixed with the impacts from geomagnetic activity, solar irradiation, and tides and waves from the lower atmosphere. We hope future observations will further our understanding of the impact of a solar eclipse as well as the basic physics of the I-T system. Our simulation data have been made available online for data-model comparisons.

\section{Summary}

We have used a coupled thermosphere-ionosphere-electrodynamics model to predict the global response of the Earth's upper atmosphere to the upcoming 21 June 2020 solar eclipse. We observed a TEC depletion of about 3 TECU, a maximum neutral temperature reduction of $30 \mathrm{~K}$, neutral wind perturbations of $30 \mathrm{~m} / \mathrm{s}$, and the generation of large-scale TADs associated with the eclipse, results which are consistent with previous investigations. However, we simulated a large TEC enhancement in the EIA region, which was surrounded by eclipse-induced TEC depletions even though that region was still covered by the shadow of the eclipse. Neutral wind perturbations, which are associated with a change in the eclipse-induced temperature and pressure gradient, play a dominant role in producing the TEC enhancement. The transequatorial transport of neutral wind perturbations decreases the EIA crest in the Southern Hemisphere and enhances the EIA crest in the Northern Hemisphere, leading to an enhancement of the TEC in the northern crest. These results provide new insights into the complicated impacts of low-latitude solar eclipses on the dynamic, energetic, and electrodynamic coupling in the I-T system. The simulated I-T changes are expected to be validated and further explored in the upcoming solar eclipse through observations such as TEC measurements, ionosondes, and satellite measurements.

\section{Acknowledgments}

This work was supported by the B-type Strategic Priority Program of the Chinese Academy of Sciences (XDB41000000), the National Natural Science Foundation of China (41831070, 41974181), and the Open Research Project of Large Research Infrastructures of the Chinese Academy of Sciences, "Study of the interaction between low- and mid-latitude atmosphere and ionosphere based on the Chinese Meridian Project." Dang T. was supported by the National Natural Science Foundation of China (41904138), the National Postdoctoral Program for Innovative Talents (BX20180286), the China Postdoctoral Science Foundation (2018M642525), and the Fundamental Research Funds for the Central Universities. The National Center for Atmospheric Research is sponsored by the National Science Foundation. Simulation data are available at http:// iono.ustc.edu.cn/expdata/Publications/Eclipse_June2020/.

\section{References}

Afraimovich, E. L., Palamartchouk, K. S., Perevalova, N. P., Chernukhov, V. V., Lukhnev, A. V., and Zalutsky, V. T. (1998). lonospheric effects of the solar eclipse of March 9, 1997, as deduced from GPS data. Geophys. Res. Lett., 25(4), 465-468. https://doi.org/10.1029/98GL00186

Anastassiadis, M., and Matsoukas, D. (1969). Electron content measurements by beacon S-66 satellite during the May 20, 1966, solar eclipse. J. Atmos. Terr. Phys., 31(9), 1217-1222. https://doi.org/10.1016/0021-9169(69)90056-7

Boitman, O. N., Kalikhman, A. D., and Tashchilin, A. V. (1999). The midlatitude ionosphere during the total solar eclipse of March 9, 1997. J. Geophys. Res.: Space Phys., 104(A12), 28197-28206. https://doi.org/10.1029/1999JA900228

Chen, G., Qi, H., Ning, B. Q., Zhao, Z. Y., Yao, M., Deng, Z. X., Li, T., Huang, S., Feng, W. C., ... Wu, C. (2013). Nighttime ionospheric enhancements induced by the occurrence of an evening solar eclipse. J. Geophys. Res.: Space Phys., 118(10), 6588-6596. https://doi.org/10.1002/jgra.50551

Curto, J. J., Heilig, B., and Piñol, M. (2006). Modeling the geomagnetic effects caused by the solar eclipse of 11 August 1999. J. Geophys. Res.: Space Phys., 111(A7), A07312. https://doi.org/10.1029/2005JA011499

Dang, T., Luan, X. L., Lei, J. H., Dou, X. K., and Wan, W. X. (2016). A numerical study of the interhemispheric asymmetry of the equatorial ionization anomaly in solstice at solar minimum. J. Geophys. Res.: Space Phys., 121(9), 9099-9110. https://doi.org/10.1002/2016JA023012

Dang, T., Lei, J. H., Wang, W. B., Burns, A., Zhang, B. Z., and Zhang, S. R. (2018a). Suppression of the polar tongue of ionization during the 21 August 2017 solar eclipse. Geophys. Res. Lett., 45(7), 2918-2925. https://doi.org/10.1002/2018GL077328

Dang, T., Lei, J. H., Wang, W. B., Zhang, B. Z., Burns, A., Le, H. J., Wu, Q., Ruan, H. B., Dou, X. K., and Wan, W. X. (2018b). Global responses of the coupled thermosphere and ionosphere system to the August 2017 Great American Solar Eclipse. J. Geophys. Res.: Space Phys., 123(8), 7040-7050. 
https://doi.org/10.1029/2018JA025566

Ding, F., Wan, W. X., Ning, B. Q., Liu, L. B., Le, H. J., Xu, G. R., Wang, M., Li, G. Z., Chen, Y. D., ... Yang, M. (2010). GPS TEC response to the 22 July 2009 total solar eclipse in East Asia. J. Geophys. Res.: Space Phys., 115(A7), A07308. https://doi.org/10.1029/2009JA015113

Duncan, R. A. (1960). The equatorial F-region of the ionosphere. J. Atmos. Terr. Phys., 18(2-3), 89-100. https://doi.org/10.1016/0021-9169(60)90081-7

Farges, T., Jodogne, J. C., Bamford, R., Le Roux, Y., Gauthier, F., Vila, P. M., Altadill, D., Sole, J. G., and Miro, G. (2001). Disturbances of the western European ionosphere during the total solar eclipse of 11 August 1999 measured by a wide ionosonde and radar network. J. Atmos. Solar-Terr. Phys., 63(9), 915-924. https://doi.org/10.1016/S1364-6826(00)00195-4

Harding, B. J., Drob, D. P., Buriti, R. A., and Makela, J. J. (2018). Nightside detection of a large-scale thermospheric wave generated by a solar eclipse. Geophys. Res. Lett., 45(8), 3366-3373. https://doi.org/10.1002/2018GL077015

Heelis, R. A., Lowell, J. K., and Spiro, R. W. (1982). A model of the high-latitude ionospheric convection pattern. J. Geophys. Res.: Space Phys., 87(A8), 6339-6345. https://doi.org/10.1029/JA087iA08p06339

Huba, J. D., and Drob, D. (2017). SAMI3 prediction of the impact of the 21 August 2017 total solar eclipse on the ionosphere/plasmasphere system. Geophys. Res. Lett., 44(12), 5928-5935. https://doi.org/10.1002/2017GL073549

Huang, C. R., Liu, C. H., Yeh, K. C., Lin, K. H., Tsai, W. H., Yeh, H. C., and Liu, J. Y. (1999). A study of tomographically reconstructed ionospheric images during a solar eclipse. J. Geophys. Res.: Space Phys., 104(A1), 79-94. https://doi.org/10.1029/98JA02531

Jakowski, N., Stankov, S. M., Wilken, V., Borries, C., Altadill, D., Chum, J., Buresova, D., Boska, J., Sauli, P., ... Canderd, L. R. (2008). Ionospheric behavior over Europe during the solar eclipse of 3 October 2005. J. Atmos. Solar-Terr. Phys., 70(6), 836-853. https://doi.org/10.1016/j.jastp.2007.02.016

Le, H. J., Liu, L. B., Yue, X. A., and Wan, W. X. (2008). The midlatitude F2 layer during solar eclipses: Observations and modeling. J. Geophys. Res.: Space Phys., 113(A8), A08309. https://doi.org/10.1029/2007JA013012

Lei, J. H., Dang, T., Wang, W. B., Burns, A., Zhang, B. Z., and Le, H. J. (2018). Longlasting response of the global thermosphere and ionosphere to the 21 August 2017 solar eclipse. J. Geophys. Res.: Space Phys., 123(5), 4309-4316. https://doi.org/10.1029/2018JA025460

Lin, C. H., Li, J. Y., Fang, T. W., Chang, P. Y., Tsai, H. F., Chen, C. H., and Hsiao, C. C. (2007). Motions of the equatorial ionization anomaly crests imaged by FORMOSAT-3/COSMIC. Geophys. Res. Lett., 34(19), L19101. https://doi.org/10.1029/2007gl030741

Luan, X. L., Wang, P., Dou, X. K., and Liu, Y. C. M. (2015). Interhemispheric asymmetry of the equatorial ionization anomaly in solstices observed by COSMIC during 2007-2012. J. Geophys. Res.: Space Phys., 120(4), 3059-3073. https://doi.org/10.1002/2014JA020820

MacPherson, B., González, S. A., Sulzer, M. P., Bailey, G. J., Djuth, F., and Rodriguez, P. (2000). Measurements of the topside ionosphere over Arecibo during the total solar eclipse of February 26, 1998. J. Geophys. Res.: Space Phys., 105(A10), 23055-23067. https://doi.org/10.1029/2000ja000145

Madhav Haridas, M. K., and Manju, G. (2012). On the response of the ionospheric $\mathrm{F}$ region over Indian low-latitude station Gadanki to the annular solar eclipse of 15 January 2010. J. Geophys. Res.: Space Phys., 117(A01), A01302. https://doi.org/10.1029/2011JA016695

Moffett, R. J., and Hanson, W. B. (1965). Effect of ionization transport on the equatorial F-region. Nature, 206(4985), 705-706.

https://doi.org/10.1038/206705a0

Nayak, C., and Yiğit, E. (2018). GPS-TEC observation of gravity waves generated in the ionosphere during 21 August 2017 total solar eclipse. J. Geophys. Res.: Space Phys., 123(1), 725-738. https://doi.org/10.1002/2017JA024845

Qian, L. Y., Burns, A. G., Emery, B. A., Foster, B., Lu, G., Maute, A., Richmond, A. D., Roble, R. G., Solomon, S. C., and Wang, W. B. (2014). The NCAR TIE-GCM: A community model of the coupled thermosphere/ionosphere system. In J. Huba, et al. (Eds.), Modeling the lonosphere-Thermosphere System (pp. 73-83). Washington, DC: John Wiley \& Sons. https://doi.org/10.1002/9781118704417.ch7

Richmond, A. D., Ridley, E. C., and Roble, R. G. (1992). A thermosphere/ionosphere general circulation model with coupled electrodynamics. Geophys. Res. Lett., 19(6), 601-604. https://doi.org/10.1029/92GL00401

Richmond, A. D. (1995). lonospheric electrodynamics using magnetic apex coordinates. J. Geomagn. Geoelectr., 47(2), 191-212. https://doi.org/10.5636/jgg.47.191

Roble, R. G., Emery, B. A., and Ridley, E. C. (1986). lonospheric and thermospheric response over Millstone Hill to the May 30, 1984, annular solar eclipse. J. Geophys. Res.: Space Phys., 91(A2), 1661-1670. https://doi.org/10.1029/JA091iA02p01661

Roble, R. G., Ridley, E. C., Richmond, A. D., and Dickinson, R. E. (1988). A coupled thermosphere/ionosphere general circulation model. Geophys. Res. Lett., 15(12), 1325-1328. https://doi.org/10.1029/GL015i012p01325

Salah, J. E., Oliver, W. L., Foster, J. C., Holt, J. M., Emery, B. A., and Roble, R. G. (1986). Observations of the May 30, 1984, annular solar eclipse at Millstone Hill. J. Geophys. Res.: Space Phys., 91(A2), 1641-1660. https://doi.org/10.1029/JA091iA02p01651

Singh, L., Tyagi, T. R., Somayajulu, Y. V., Vijayakumar, P. N., Dabas, R. S., Loganadham, B., Ramakrishna, S., Rama Rao, P. V. S., Dasgupta, A., ... Hartmann, G. K. (1989). A multi-station satellite radio beacon study of ionospheric variations during total solar eclipses. J. Atmos. Terr. Phys., 51(4), 271-278. https://doi.org/10.1016/0021-9169(89)90078-0

St.-Maurice, J.-P., Ambili, K. M., and Choudhary, R. K. (2011). Local electrodynamics of a solar eclipse at the magnetic equator in the early afternoon hours. Geophys. Res. Lett., 38(4), L04102. https://doi.org/10.1029/2010GL046085

Sun, Y. Y., Liu, J. Y., Lin, C. C. H., Lin, C. Y., Shen, M. H., Chen, C. H., Chen, C. H., and Chou, M. Y. (2018). lonospheric bow wave induced by the moon shadow ship over the continent of United States on 21 August 2017. Geophys. Res. Lett., 45(2), 538-544. https://doi.org/10.1002/2017GL075926

Wang, W. B., Dang, T., Lei, J. L., Zhang, S. R., Zhang, B. Z., and Burns, A. (2019). Physical processes driving the response of the $F_{2}$ region ionosphere to the 21 August 2017 solar eclipse at Millstone Hill. J. Geophys. Res.: Space Phys., 124(4), 2978-2991. https://doi.org/10.1029/2018ja025479

Zhang, S. R., Erickson, P. J., Goncharenko, L. P., Coster, A. J., and Frissell, N. A. (2017a). Monitoring the geospace response to the Great American Solar Eclipse on 21 August 2017. Earth Planet. Phys., 1(1), 72-76. https://doi.org/10.26464/epp2017011

Zhang, S. R., Erickson, P. J., Goncharenko, L. P., Coster, A. J., Rideout, W., and Vierinen, J. (2017b). lonospheric bow waves and perturbations induced by the 21 August 2017 Solar Eclipse. Geophys. Res. Lett., 44(24), 12067-12073. https://doi.org/10.1002/2017GL076054 